Scientific paper

\title{
The Eccentricity Version of Atom-Bond Connectivity Index of Linear Polycene Parallelogram Benzenoid $A B C_{5}(P(n, n))$
}

\author{
Wei Gao, ${ }^{1}$ Mohammad Reza Farahani ${ }^{2}$ and Muhammad Kamran Jamil ${ }^{3, *}$ \\ ${ }^{1}$ School of Information Science and Technology, Yunnan Normal University, Kunming 650500, China. \\ ${ }^{2}$ Department of Applied Mathematics of Iran University of Science and Technology (IUST), \\ Narmak, Tehran 16844, Iran. \\ ${ }^{3}$ Department of Mathematics, Riphah Institute of Computing and Applied Sciences (RICAS), Riphah International University, \\ 14 Ali Road, Lahore, Pakistan. \\ * Corresponding author: E-mail: m.kamran.sms@gmail.com \\ Phone: +923464105447
}

Received: 23-02-2016

\begin{abstract}
Among topological descriptors, connectivity indices are very important and they have a prominent role in chemistry. The atom-bond connectivity index of a connected graph $G$ is defined as $A B C(G)=\sum_{\| v \in(G)} \sqrt{\frac{d_{v}+d_{v}-2}{d_{a} d_{v}}}$, where $d_{v}$ denotes the degree of vertex $v$ of $G$ and the eccentric connectivity index of the molecular graph $G$ is defined as $\xi(G)=\sum_{v d^{\prime}} d_{v} \times \varepsilon(v)$, where $\varepsilon(v)$ is the largest distance between $v$ and any other vertex $u$ of $G$. Also, the eccentric atombond connectivity index of a connected graph $G$ is equal to $A B C_{5}(G)=\sum_{u, E(G)} \sqrt{\frac{\varepsilon(u)+\varepsilon(v)-2}{\varepsilon(u) \varepsilon(v)}}$.

In this present paper, we compute this new Eccentric Connectivity index for an infinite family of Linear Polycene Parallelogram Benzenoid.
\end{abstract}

Keywords: Molecular graph, Atom-bond connectivity index; Eccentricity connectivity index, Linear Polycene Parallelogram Benzenoid

\section{Introduction}

Let $G=(V, E)$ be a graph, where $V(G)$ is a non-empty set of vertices and $E(G)$ is a set of edges. In chemical graph theory, there are many molecular descriptors (or Topological Index) for a connected graph, that have very useful properties to study of chemical molecules. ${ }^{1-4}$ This theory had an important effect on the development of the chemical sciences.

A topological index of a graph is a number related to a graph which is invariant under graph automorphisms. Among topological descriptors, connectivity indices are very important and they have a prominent role in chemistry.
One of them is Atom-Bond Connectivity $(A B C)$ index of a connected graph $G=(V, E)$ and defined as

$$
A B C(G)=\sum_{w \in E \in G(G)} \sqrt{\frac{d_{w}+d_{v}-2}{d_{u} d_{v}}},
$$

where $d_{v}$ denotes the degree of vertex $v$ of $G$, that introduced by Furtula et.al. ${ }^{5,6}$

On the other hands, Sharma, Goswami and Madan ${ }^{7}$ (in 1997) introduced the eccentric connectivity index of the molecular graph $G$ as

$$
\xi(G)=\sum_{v J^{J}} d_{v} \times \varepsilon(v),
$$


where $\varepsilon(u)$ is the largest distance between $u$ and any other vertex $v$ of $G$. If $x, y \in V(G)$, then the distance $d(x, y)$ between $x$ and $y$ is defined as the length of any shortest path in $G$ connecting $x$ and $y$. In other words, is maximum distance with first-point $v$ in $G$.

$$
\varepsilon(v)=\operatorname{Max}\{d(v, u) \mid \forall v \in V(G)\}
$$

The Eccentric Connectivity polynomial of a graph $G$, was defined by Alaeiyan, Mojarad and Asadpour as follows: 8,9

$$
\operatorname{ECP}(G, x)=\sum_{v \in V(G)} d_{v} x^{e c c(v)} .
$$

Alternatively, the eccentric connectivity index is the first derivative of $\operatorname{ECP}(G ; x)$ evaluated at $x=1$. Now, by combine these above topological indexes, we now define a new version of $A B C$ index as: ${ }^{10}$

$$
\begin{aligned}
& A B C_{5}(G)=\sum_{4 v \in E(G)} \sqrt{\frac{\varepsilon(u)+\varepsilon(v)-2}{\varepsilon(u) \varepsilon(v)}} \cdot \\
& A B C_{5}(P(n, n))=4 \sum_{i=1}^{n-1}\left[\sqrt{\frac{8 n-4 i-1}{4 i^{2}-2(4 n+1) i+4 n(4 n+1)}}+\sqrt{\frac{8 n-4 i-3}{4 i^{2}-2(4 n-1) i+4 n(4 n-1)}}\right. \\
& \left.+(i) \sqrt{\frac{8 n-4 i-5}{4 i^{2}-2(8 n-3) i+2\left(8 n^{2}-6 n+1\right)}}+\frac{i}{2} \sqrt{\frac{8 n-4 i-7}{4 i^{2}-2(8 n+1) i+2\left(8 n^{2}-10 n+3\right)}}\right]+\left[\frac{8 \sqrt{n}}{(2 n+1)}+(n-1) \frac{\sqrt{4 n-2}}{n}-2(n-1) \sqrt{\frac{4 n+1}{4 n^{2}-8 n+5}}\right] .
\end{aligned}
$$

cal index for an infinite family of Linear Polycene Parallelogram Benzenoid.

\section{Main Results and Discussion}

In this section, we computed the Eccentric atombond connectivity index $A B C_{5}$ of an infinite family of Linear Polycene Parallelogram of Benzenoid graph, ${ }^{19}$ by continuing the results from. ${ }^{8,9,18,19}$ This Molecular graph has $2 n(n+2)$ vertices and $3 n^{2}+4 n-1$ edges.

For further study and more detail representation of Linear Polycene Parallelogram of Benzenoid $P(n, n)$, see..$^{8,9,18,19}$ Also, reader can see the general case of this Benzenoid molecular graph in Figure 1.

The general representation of Linear Polycene Parallelogram of Benzenoid $P(n, n)$ is shown in Figure1.

Theorem 1. Let $P(n, n)(\forall n \in \mathbb{N})$ be the Linear Polycene Parallelogram of benzenoid. Then the Eccentric atom-bond Connectivity index $A B C_{5}$ of $P(n, n)$ is
We denote this new index of a connected graph $G$ (Eccentric atom-bond connectivity index) by $A B C_{5}(G)$ (Since it is fifth definition of $A B C$ index). For more details about the Atom-Bond Connectivity and Eccentricity connectivity indices see paper series. ${ }^{11-18}$

The aim of this paper is to exhibit this new topologi-
Proof: Let $(\forall n \geq 1) P(n, n)$ depicted in Figure 1 be the general representation of Linear Polycene Parallelogram Benzenoid graph with $2 n(n+2)$ vertices, such that $4 n+2$ of them have degree two and $2 n^{2}-2$ have degree three $\left(V\left(P(n, n)=V_{2} \cup V_{3}\right)\right.$. Thus there are $3 n^{2}+4 n-1 \quad(=1 / 2[2(4 n$ $\left.\left.+2)+3\left(4 n^{2}-2\right)\right]\right)$ edges.

Table 1. Eccentric connectivity index for all vertices of Linear Polycene Parallelogram Benzenoid graph $P(n, n) .{ }^{8,9}$

\begin{tabular}{|l|l|l|l|l|l|l|l|l|}
\hline $2 n+1$ & $2 n+1$ & $2 n+2$ & $\ldots$ & $4 n-5$ & $4 n-4$ & $4 n-3$ & $4 n-2$ & $4 n-1$ \\
\hline $2 n$ & $2 n+1$ & $2 n+2$ & $\ldots$ & $4 n-5$ & $4 n-4$ & $4 n-3$ & $4 n-2$ & \\
\hline $2 n$ & $2 n+1$ & $2 n+2$ & $\ldots$ & $4 n-5$ & $4 n-4$ & & & \\
\hline $2 n$ & $2 n+1$ & $2 n+2$ & $\ldots$ & & & & & \\
\hline$\ldots$ & $\ldots$ & $\ldots$ & & & & & & \\
\hline$\ldots$ & $\ldots$ & $\ldots$ & & & & & & \\
\hline$\ldots$ & $\ldots$ & $\ldots$ & & & & & & \\
\hline $2 n$ & $2 n+1$ & $2 n+2$ & & & & & & \\
\hline & $2 n+1$ & & & & & & & \\
\hline
\end{tabular}




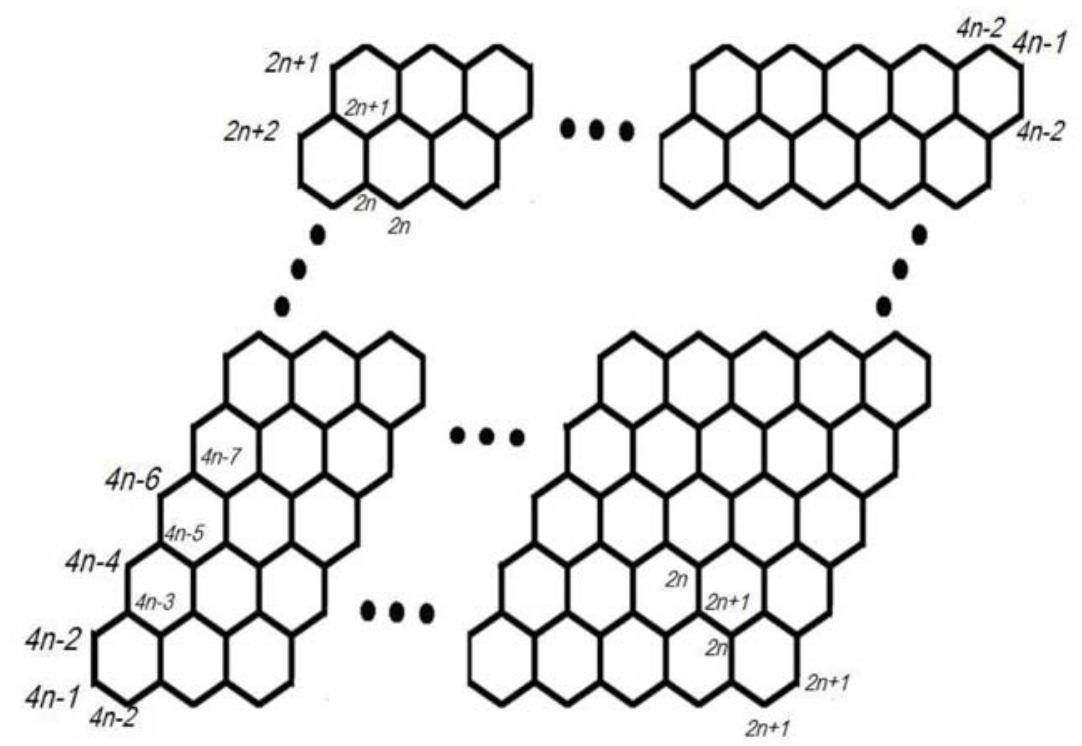

Figure 1. $\forall n \in \mathbb{N}$ the general representation of Linear Polycene Parallelogram of Benzenoid $P(n, n)$ and the eccentric connectivity of its vertices.

Now by refer to, ${ }^{8,9,16}$ we have the maximum eccentric connectivity and minimum eccentric connectivity for a $v \in V(P(n, n))$ as $\operatorname{Max}_{\varepsilon(v)}=4 n-1$ and $\operatorname{Min}_{\varepsilon(v)}=2 n$.

Now by according to Figure 1 and Table 1, it is easy see that:

- For all vertices with degree two in $P(n, n)$, the ec- centricity are equal to $4 n-1,4 n-2,4 n-4,4 n-6, \ldots$, $2 n+2,2 n+1$.

- For all other vertices with degree three $P(n, n)\left(d_{v}=\right.$ $3)$, the eccentricity are equal to $4 n-3$ until $2 n$.

Thus, we have following computations by using Figure 1 and results in Table 1 as:

$$
\begin{aligned}
& A B C_{5}(P(n, n))=\sum_{\varepsilon=v \in E(P(n, n))} \sqrt{\frac{\varepsilon(u)+\varepsilon(v)-2}{\varepsilon(u) \varepsilon(v)}}
\end{aligned}
$$

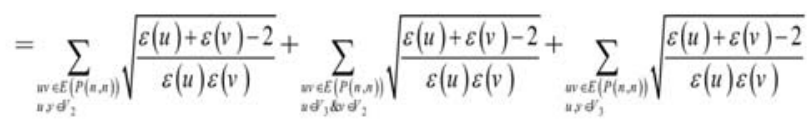

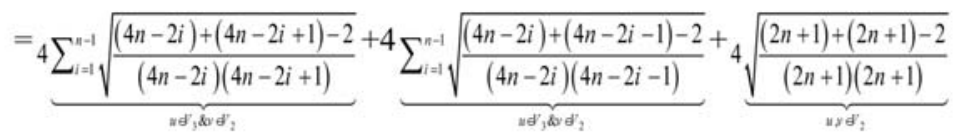

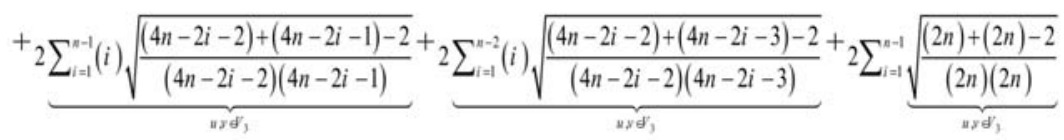

$$
\begin{aligned}
& +\underbrace{}_{=\underbrace{}_{i=1} \sum_{i=1}^{n-1}(i) \sqrt{\frac{(4 n-2 i-2)+(4 n-2 i-1)-2}{(4 n-2 i-(4 n-2 i-1)}}} \\
& =4 \sum_{i=1}^{n-1} \sqrt{\frac{(4 n-2 i)+(4 n-2 i+1)-2}{(4 n-2 i)(4 n-2 i+1)}}+4 \sum_{i=1}^{n-1} \sqrt{\frac{(4 n-2 i)+(4 n-2 i-1)-2}{(4 n-2 i)(4 n-2 i-1)}}++\frac{8 \sqrt{n}}{(2 n+1)} \\
& +4 \sum_{i=1}^{n-1}(i) \sqrt{\frac{(4 n-2 i-2)+(4 n-2 i-1)-2}{(4 n-2 i-2)(4 n-2 i-1)}}+2 \sum_{i=0}^{n-3}(i+1) \sqrt{\frac{(4 n-2 i)+(4 n-2 i-1)-2}{(4 n-2 i)(4 n-2 i-1)}}+(n-1) \frac{\sqrt{4 n-2}}{n} \\
& =4 \sum_{i=1}^{n-1} \sqrt{\frac{8 n-4 i-1}{4 i^{2}-2(4 n+1) i+4 n(4 n+1)}}+4 \sum_{i=1}^{n-1} \sqrt{\frac{8 n-4 i-3}{4 i^{2}-2(4 n-1) i+4 n(4 n-1)}}+\frac{8 \sqrt{n}}{(2 n+1)} \\
& +4 \sum_{i=1}^{n-1}(i) \sqrt{\frac{8 n-4 i-5}{4 i^{2}-2(8 n-3) i+2\left(8 n^{2}-6 n+1\right)}}+2 \sum_{i=1}^{n-2}(i) \sqrt{\frac{8 n-4 i-7}{4 i^{2}-2(8 n+1) i+2\left(8 n^{2}-10 n+3\right)}}+(n-1) \frac{\sqrt{4 n-2}}{n} .
\end{aligned}
$$


Finally, $\forall n \in \mathbb{N}$, the fifth $\mathrm{ABC}$ index of Linear Polycene Parallelogram Benzenoid $P(n, n)$ is equal to:

$$
\begin{gathered}
A B C_{5}(P(n, n))=4 \sum_{=1}^{n-1}\left[\sqrt{\frac{8 n-4 i-1}{4 i^{2}-2(4 n+1) i+4 n(4 n+1)}}+\sqrt{\frac{8 n-4 i-3}{4 i^{2}-2(4 n-1) i+4 n(4 n-1)}}+(i) \sqrt{\frac{8 n-4 i-5}{4 i^{2}-2(8 n-3) i+2\left(8 n^{2}-6 n+1\right)}}+\frac{i}{2} \sqrt{\frac{8 n-4 i-7}{4 i^{2}-2(8 n+1) i+2\left(8 n^{2}-10 n+3\right)}}\right] \\
+\left[\frac{8 \sqrt{n}}{(2 n+1)}+(n-1) \frac{\sqrt{4 n-2}}{n}-2(n-1) \sqrt{\frac{4 n+1}{4 n^{2}-8 n+5}}\right] .
\end{gathered}
$$

Here, we complete the proof of Theorem 1.

\section{Conclusions}

In this paper, we consider a family of Linear Polycene Parallelogram Benzenoid and compute the Eccentric atom-bond Connectivity index $A B C_{5}$. The Eccentric atombond Connectivity index $A B C_{5}$ was defined as $A B C_{5}(G)=\sum_{u \in E(G)} \sqrt{\frac{\varepsilon(u)+\varepsilon(v)-2}{\varepsilon(u) \varepsilon(v)}}$, such that $\varepsilon(v)(\operatorname{Max}\{d(v$, $u) \mathbb{N} \forall v \in V(G)\})$ is the largest distance between $v$ and any other vertex $u$ of $G$.

\section{References}

1. I. Gutman, N. Trinajstić, Chem. Phys. Lett. 1972, 17, 535-538. http://dx.doi.org/10.1016/0009-2614(72)85099-1

2. D. A. Klarner, Polyominoes, In: J. E. Goodman, J. O'Rourke, (eds.) Handbook of Discrete and Computational Geometry, CRC Press, Boca Raton, 1997, 12, 225-242.

3. M. Randić, J. Am. Chem. Soc. 1975, 97, 6609-6615. http://dx.doi.org/10.1021/ja00856a001

4. N. Trinajstić, Chemical Graph Theory. CRC Press, Boca Raton, FL., 1992.

http://dx.doi.org/10.1007/s10910-009-9520-x
5. D. Vukicevic, B. Furtula, J. Math. Chem. 2009, 46, 13691376.

6. E. Estrada, L. Torres, L. Rodriguez, I. Gutman, Indian J. Chem. 1998, 37A, 849-855.

7. V. Sharma, R. Goswami, A. K. Madan, J. Chem. Inf. Comput. Sci. 1997, 37, 273-282. http://dx.doi.org/10.1021/ci960049h

8. M. Alaeiyan, R. Mojarad, J. Asadpour, Optoelectron. Adv. Mater-Rapid Commun. 2011, 5, 761-763.

9. M. Alaeiyan, J. Asadpour, Optoelectron. Adv. Mater-Rapid Commun. 2012, 6, 191-193.

10. M. R. Farahani, World Appl. Sci. J., 2013, 21, 1260-1265.

11. A. R. Ashrafi, M. Ghorbani, M. Hemmasi, Digest. J. Nanomater. Bios., 2009, 4, 483-486.

12. S. Alikhani, M. A. Iranmanesh, Digest. J. Nanomater. Bios. 2011, 6, 253-257.

13. I. Gutman, O. E. Polansky, Mathematical Concepts in Organic Chemistry, Springer-Verlag, New York, 1986. http://dx.doi.org/10.1007/978-3-642-70982-1

14. M. A. Johnson, G. M. Maggiora, Concepts and Applications of Molecular Similarity, Wiley Interscience, New York, 1990.

15. M. R. Farahani, Acta Chim. Slov. 2012, 59, 779-783.

16. M. R. Farahani, Acta Chim. Slov. 2013, 60, 429-432.

17. M. R. Farahani, An. Univ. Vest Timis. Ser. Mat.-Inform. 2013, 51, 29-37.

18. M. R. Farahani, Int. Lett. Chem. Phys. Astron. 2014, 18, 57-62.

19. P. V. Khadikar, Iran. J. Math. Chem. 2010, 1, 7-42.

\section{Povzetek}

Med topološkimi deskriptorji so indeksi povezanosti izredno pomembni in imajo vidno vlogo v kemiji. Indeks atomske povezanosti grafa $\mathrm{G}$ je definiran $\operatorname{kot} A B C(G)=\sum_{v \in \mathcal{E}(\sigma)} \sqrt{\frac{d_{v}+d_{v}-2}{d_{s} d_{v}}}$, kjer je $d_{v}$ stopnja vozliš̌ča (točke) $v$ od $G$ ter je ecentrični indeks povezanosti grafa $G$ definiran kot $\xi(G)=\sum_{v \in J} d_{v} \times \varepsilon(v)$, kjer je $\varepsilon(v)$ najdaljša razdalja med $v$ in katerim koli vozliščem $u \operatorname{od} G$. Poleg tega je ecentrični indeks atomske povezanosti povezanega grafa $G$ enak $A B C_{5}(G)=$ $=\sum_{u v \in(G)} \sqrt{\frac{\varepsilon(u)+\varepsilon(v)-2}{\varepsilon(u) \varepsilon(v)}}$.

V tem članku smo izračunali novi ecentrični indeks povezanosti za neskončno družino linearnih policenskih paralelogramskih benzenoidov. 